\title{
Electrospray Ionization-Mass Spectrometric Measurement of Sake, a Traditional Japanese Alcohol Beverage, for Characterization
}

\author{
Hiroshi Moriwaki, ${ }^{\dagger}$ Ayaka Hagiwara, Midori Takasaki, Fuminori Izumi, Arata Watanabe, \\ Ryo ShImizu, Natsuko KURIBayashi, Yui Totani, and Yuka SuZUKI
}

\author{
Shinshu University, Faculty of Textile Science and Technology, Division of Applied Biology,
} 3-15-1 Tokida, Ueda 386-8567, Japan

\begin{abstract}
A rapid method for the characterization of sake by measuring the ratio of the peak intensities of taste components in sake, using electrospray ionization/mass spectrometry (ESI/MS) has been developed. Twenty-six different kinds of sake samples were collected and analyzed by ESI/MS. The ESI/MS ion peaks were assigned to amino acids, organic acids, and sugars. Principal component analysis was performed using the respective peak intensities obtained by ESI/MS measurements. As a result, the cumulative proportion of the two first principal components was over $70 \%$, and these components could be used for the characterization of sake.
\end{abstract}

(Received November 16, 2009; Accepted December 18, 2009; Published March 10, 2010)

\section{Introduction}

Sake is a traditional Japanese alcohol beverage, which is made from steamed rice using multiple fermentations of rice malt (Aspergillus oryzae) and sake yeast (Saccharomyces cerevisiae). Sake has been produced and marketed by many brewing companies, and the amount of consumption in 2007 was $717153 \mathrm{~kL} .{ }^{1}$

It is difficult to perform the sake brewing process and to control the quality, due to the complexity of parallel fermentations. The contents of the flavor and taste components of sake are very important parameters concerning its quality. ${ }^{2}$ Several studies have been made on the analysis of flavor components, which are volatile compounds, using gas chromatography/mass spectrometry (GC/MS). ${ }^{3-5}$ The taste of sake is generally represented by two parameters. One is an indicator of the sweet taste based on the density of the sake sample, and the other is that of sour taste measured by the total quantity of organic acid compounds. Using these two indicators, the taste of sake is classified as "kara-kuchi", which means brut taste in Japanese, or "ama-kuchi", the sweet taste. However, such a classification is obscure for consumers, and a novel characterization of sake is needed.

Araújo et al. has reported a method for the rapid characterization of beer, using electrospray ionization/mass spectrometry (ESI/MS). ${ }^{6}$ ESI/MS has also been applied to the characterization of whiskey, ${ }^{7}$ wine ${ }^{8}$ and Brazilian cachaça. ${ }^{9}$ The method is to characterize beer by the ratio of the peak intensities of the ion peaks in the taste components, such as sugars, amino acids, and organic acids, measured by ESI/MS.

It is well known that these compounds are also related to the tastes of sake. ${ }^{10}$ The characterization of sake by the composition ratio of various chemicals related to tastes has not been

$\dagger$ To whom correspondence should be addressed.

E-mail: moriwaki@shinshu-u.ac.jp established at this stage. In this study, we developed a rapid method for the characterization of sake by measuring the taste components by ESI/MS.

\section{Experimental}

\section{Materials}

Twenty-six different kinds of sake samples were purchased at random from various liquor stores. Formic acid, ammonia hydroxide and methanol were obtained from Wako Pure Chemical Industries (Osaka, Japan).

\section{Experimental procedures}

An analysis of the samples was performed according to a modification made to the procedure described in Ref. 6. Sake samples were analyzed by ESI/MS in the positive and negative ion modes. A mass spectrometer, LC/MS 2010 A (Shimadzu, Kyoto, Japan), was used for ESI/MS measurements of sake. The ESI/MS conditions were: scan range, $m / z$. $50-1000$; heat block temperature, $200^{\circ} \mathrm{C}$; interface voltage, $4.5 \mathrm{kV}$ for positive ion mode and $-3.5 \mathrm{kV}$ for negative ion mode; CDL voltage, $20 \mathrm{~V}$ for positive ion mode and $-20 \mathrm{~V}$ for negative ion mode. Each sample $(250 \mu \mathrm{L})$ of sake was diluted with $250 \mu \mathrm{L}$ of $\mathrm{MeOH}$ and $500 \mu \mathrm{L}$ of water. Formic acid $(2 \mu \mathrm{L})$ was added to the sample solution for the ESI/MS measurement in the positive ion mode. Ammonium hydroxide $(2 \mu \mathrm{L})$ was added to the sample solution for the ESI/MS measurement in the negative ion mode. The samples were injected by a syringe pump (IC3100, KD Scientific, MA) attached to the LC/MS system. The flow rate was $50 \mu \mathrm{L} \mathrm{min}{ }^{-1}$. The peak intensities were obtained from the average of 30 scans.

\section{Statistical treatment}

To characterize the sake samples from the results of ESI/MS measurements, a principal component analysis was performed. Twenty-three ion peaks in the negative ion mode were selected 
Table 1 Possible assignment of the ion peaks detected by ESI/MS in the positive and negative ion mode

\begin{tabular}{|c|c|c|c|c|c|}
\hline \multicolumn{2}{|r|}{ ESI/MS (+) } & \multicolumn{2}{|r|}{ ESI/MS (-) } & \multicolumn{2}{|c|}{ Component loading } \\
\hline $\begin{array}{l}\text { Detected ion } \\
\text { peak }(\mathrm{m} / \mathrm{z})\end{array}$ & Possible assignment of the ion peak & $\begin{array}{c}\text { Detected ion } \\
\text { peak }(m / z)\end{array}$ & Possible assignment of the ion peak & PC1 & PC2 \\
\hline 175 & {$[\text { Arginine }+\mathrm{H}]^{+}$} & 89 & {$[\text { Lactose- }-\mathrm{H}]^{-}$} & 0.675 & -0.184 \\
\hline 203 & {$[\text { Glucose }+\mathrm{Na}]^{+}$} & 117 & {$[\text { Succinic acid-H }]^{-}$} & 0.877 & 0.097 \\
\hline 231 & 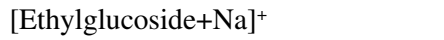 & 133 & {$[\text { Malic acid-H }]^{-}$} & 0.526 & 0.498 \\
\hline 247 & {$[\text { Ethylglucoside }+\mathrm{K}]^{+}$} & 146 & [Glutamic acid-H] $]^{-}$ & 0.789 & -0.312 \\
\hline 277 & [Glucosylglycerol+Na] $^{+}$ & 191 & {$[\text { Citric acid-H }]^{-}$} & 0.703 & 0.562 \\
\hline 293 & {$[\text { Glucosylglycerol+K }]^{+}$} & $215(217)^{\mathrm{a}}$ & 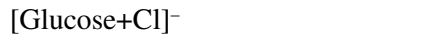 & 0.775 & -0.563 \\
\hline 365 & {$[\text { Maltose }+\mathrm{Na}]^{+},[\text {sucrose }+\mathrm{Na}]^{+}$} & $243(245)^{\mathrm{a}}$ & [Ethylglucoside+Cl] $]^{-}$ & 0.882 & -0.066 \\
\hline 381 & {$[\text { Maltose }+\mathrm{K}]^{+},[\text {sucrose }+\mathrm{K}]^{+}$} & 253 & [Glucosylglycerol-H]- & 0.937 & -0.018 \\
\hline 393 & 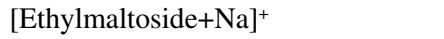 & $289(291)^{\mathrm{a}}$ & [Glucosylglycerol+Cl] $^{-}$ & 0.852 & -0.474 \\
\hline 409 & {$[\text { Ethylmaltoside }+\mathrm{K}]^{+}$} & 369 & {$[\text { Ethylmaltoside }-\mathrm{H}]^{-}$} & 0.897 & 0.072 \\
\hline 439 & [Diglucosylglycerol+Na] $^{+}$ & $377(379)^{\mathrm{a}}$ & {$[\text { Maltose }+\mathrm{Cl}]^{-},[\text {sucrose }+\mathrm{Cl}]^{-}$} & 0.681 & -0.404 \\
\hline 455 & 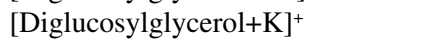 & $405(407)^{\mathrm{a}}$ & {$[\text { Ethylmaltoside }+\mathrm{Cl}]^{-}$} & 0.861 & -0.195 \\
\hline 527 & {$[\text { Maltotriose+Na }]^{+}$} & 415 & [Diglucosylglycerol-H] $^{-}$ & 0.860 & -0.042 \\
\hline 543 & {$[\text { Maltotriose }+\mathrm{K}]^{+}$} & 439 & Oligosaccharide I & 0.707 & -0.004 \\
\hline 601 & [Triglucosylglycerol+Na] $^{+}$ & $451(453)^{\mathrm{a}}$ & [Diglucosylglycerol+Cl] $^{-}$ & 0.866 & -0.173 \\
\hline 617 & 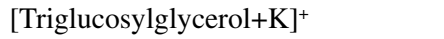 & 503 & {$[\text { Maltotriose-H }]^{-}$} & 0.794 & 0.015 \\
\hline 689 & {$[\text { Maltotetrose }+\mathrm{Na}]^{+}$} & $539(541)^{\mathrm{a}}$ & {$[\text { Maltotriose }+\mathrm{Cl}]^{-}$} & 0.723 & -0.307 \\
\hline 705 & {$[\text { Maltotetrose }+\mathrm{K}]^{+}$} & 601 & Oligosaccharide II & 0.679 & 0.033 \\
\hline 851 & 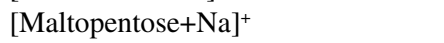 & 665 & [Maltotetrose-H] $]^{-}$ & 0.755 & 0.397 \\
\hline \multirow[t]{4}{*}{867} & {$[\text { Maltopentose+K }]^{+}$} & $701(703)^{\mathrm{a}}$ & {$[\text { Maltotetrose+Cl] }]^{-}$} & 0.790 & 0.122 \\
\hline & & 763 & Oligosaccharide III & 0.788 & 0.426 \\
\hline & & 827 & {$[\text { Maltopentose- } \mathrm{H}]^{-}$} & 0.593 & 0.642 \\
\hline & & 925 & Oligosaccharide IV & 0.285 & 0.653 \\
\hline
\end{tabular}

a. The values in parenthesis are $\mathrm{m} / \mathrm{z}$ of the ion peaks correspond to the ${ }^{37} \mathrm{Cl}$ adducts, and the ion peaks correspond to the ${ }^{37} \mathrm{Cl}$ adducts were not added as parameters in principle component analysis.

as variables (Table 1), because these ion peaks could be assigned to the ions that arose from the molecules that have been reported as components in alcohol beverages. The peak intensities in the mass spectra were used for a statistical treatment. The data matrix constituted of 26 samples (as rows) and the group of variables (as columns) was used for principal component analysis.

\section{Results and Discussion}

\section{ESI/MS spectra}

Typical ESI/MS spectra of samples in the positive and negative ion mode are shown in Figs. 1 and 2, respectively. Similar ion peaks were detected in ESI/MS measurements for every sample, and the ratio of peak intensities showed individual differences among them. For example, in the mass spectrum for sample No. 22 (Fig. 1), the ion peak at $\mathrm{m} / \mathrm{z} 175$ was well observed. On the other hand, the mass spectrum for sample No. 5 showed a very weak peak at $\mathrm{m} / \mathrm{z} 175$.

Possible assignments of detected ion peaks are summarized in Table 1. Ion peaks corresponding to sodium and potassium adducts of glucose, maltose, sucrose, maltotriose, maltotetrose, and maltopentose were observed by ESI/MS in the positive ion mode. It has been reported that these sugars are contained in sake, and they affect taste. ${ }^{11}$ It is well known that ethylglucoside and glycosylglycerols are unique components in sake, ${ }^{12,13}$ and cations of sodium and potassium adducts in these compounds were also observed. In the negative ion mode, deprotonated organic acids (succinic acid, malic acid, glutamic acid, and citric acid) were detected. It is well known that these organic acids play an important role concerning the taste of sake. ${ }^{14}$ Anions of $\mathrm{m} / \mathrm{z}, 503,665$ and 827 could be assigned to the [M-H] of maltotriose, maltotetrose, and maltopentose, respectively. In addition, ion peaks corresponding to chloride adducts of glucose, maltose, sucrose, maltotriose, maltotetrose, maltopentose, ethylglucoside, and glycosylglycerols were observed. The ions of $\mathrm{m} / \mathrm{z}, 439,601,763$ and 925 correspond to the unfermentable oligosaccharides, because the differences of $m / z$ among these ions were $162\left(\mathrm{C}_{6} \mathrm{H}_{10} \mathrm{O}_{5}\right)_{\mathrm{n}}$. These ion peaks were also observed in beer samples described in Ref. 6.

Ion peaks related to organic acids were not detected in the positive ion mode. On the other hand, most of the compounds detected in the positive ion mode were also detected in the negative ion mode.

\section{Principal component analysis}

Principal component analysis was conducted using the peak intensities of ions detected by ESI/MS in the negative ion mode, because the number of ion peaks assigned to sake components by ESI/MS in the negative ion mode was greater than those in the positive ion mode (Table 1).

The cumulative proportion of principal component 1 (PC1) and PC2 was over $70 \%$, and these two components were used for the characterization of sake. The values of component loading for ion peaks are given in Table 1 . The values of component loading for most ion peaks in PC1 did not show major differences. Therefore, PC1 would be controlled by the total composition of the taste compounds. On the other hand, the values of component loading for ion peaks corresponding to malic acid, citric acid, and saccharides (molecular weight $>600$ ) in PC2 were higher than those of the other ion peaks. Thus, PC2 would be controlled by the constituents related to acid and sweet tastes of sake. Scores of these two principal components were calculated and plotted (Fig. 3). Samples (Nos. 1, 2, 24, 25 , and 26) belonged to the group called "gousei-seishu" 


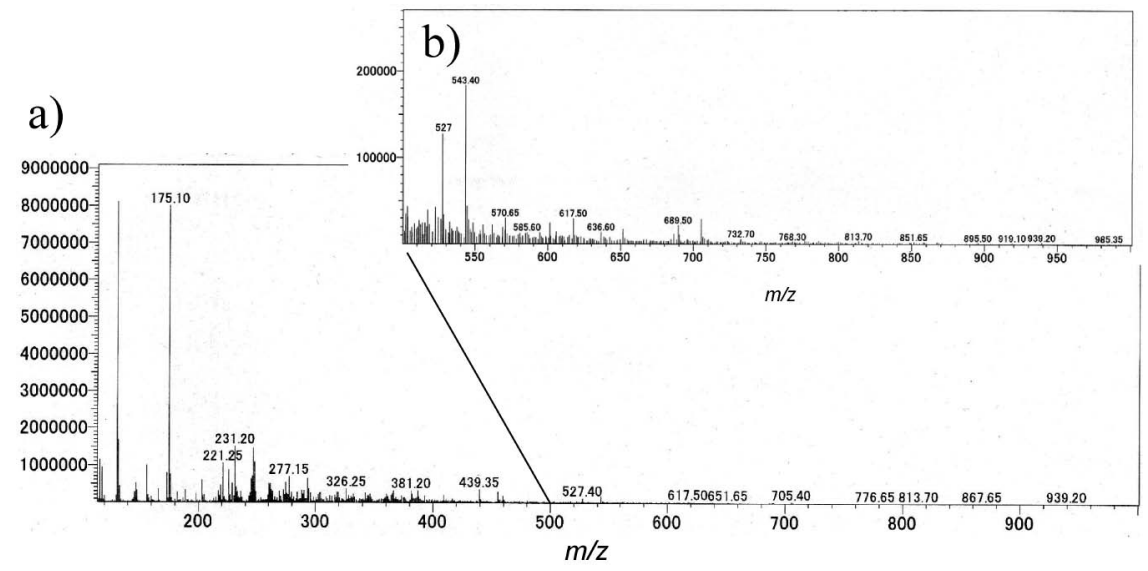

Fig. 1 a) ESI/MS spectrum of a sake sample (sample No. 22) in the positive ion mode, b) $\mathrm{m} / \mathrm{z}$ $500-950$.

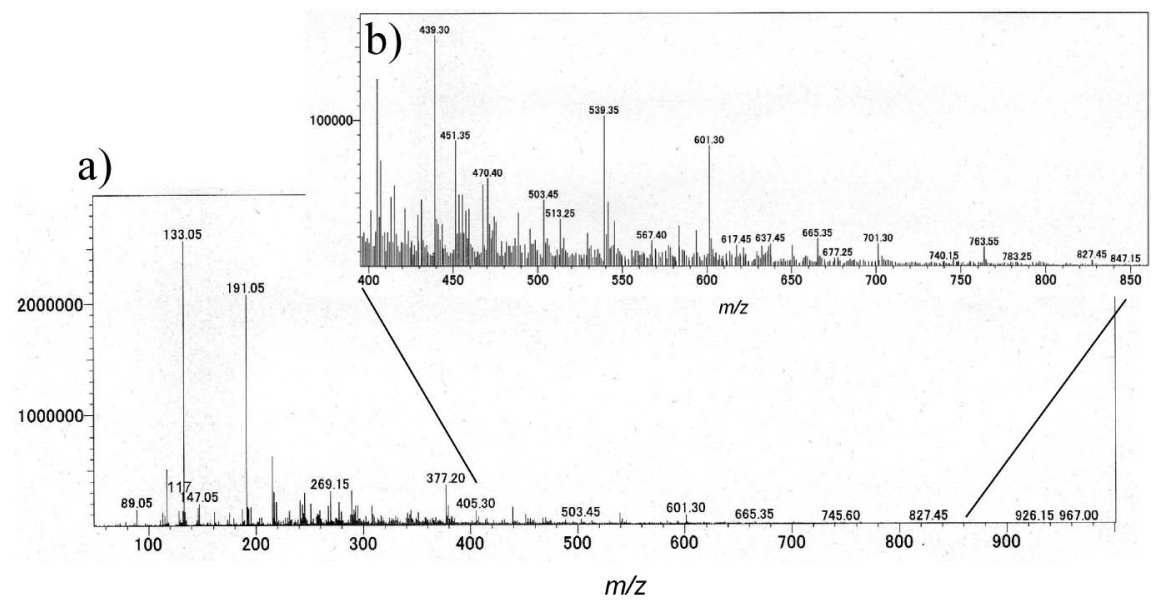

Fig. 2 a) ESI/MS spectrum of a sake sample (sample No. 22) in the negative ion mode, b) $\mathrm{m} / \mathrm{z}$ $400-850$.

(synthetic sake), which had seasoning agents, such as amino acids and sugars added to them. The plots of these samples are distributed in a cluster on the left side in Fig. 3. This result indicates that the ratios of the contents in synthetic sake are totally different from those of genuine sake, which are without the addition of amino acids or sugars. It is suggested that this method can simply distinguish whether a sample is synthetic sake or not. However, there was no significant relationship between the distribution of plots and the conventional characterization of sake, such as "ama-kuchi" or "kara-kuchi", alcohol concentration, sugar contents and areas of production, except for samples 5 and 14, which were made at the same brewery. This fact indicates that characterization by this method is different from the conventional characterization of sake. In addition, we obtained $\mathrm{PC} 1 \times \mathrm{PC} 2$ plots based on data from ESI/MS in the positive ion mode. The distribution of plots was similar to that in the negative ion mode. Furthermore, we built a three-dimension plot using $\mathrm{PC} 1 \times \mathrm{PC} 2 \times \mathrm{PC} 3$ based on data from ESI/MS in the negative ion mode. In PC3, the values of component loading for ion peaks corresponding to maltose and oligosaccharides were higher than those of the other ion peaks. As a result, it was difficult to find any new tendencies in the distribution of $\mathrm{PC} 1 \times \mathrm{PC} 2 \times \mathrm{PC} 3$ plots compared to the

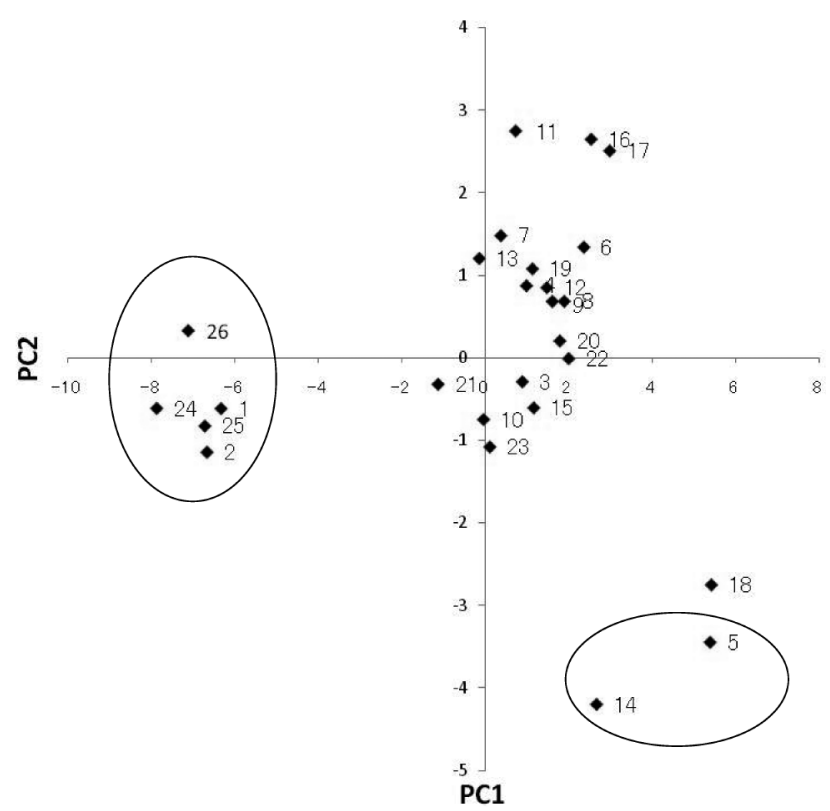

Fig. 3 Scores of $\mathrm{PC} 1$ versus $\mathrm{PC} 2$ for ESI/MS data in the negative ion mode. The data labels are the number on samples. 
PC1 $\times$ PC2 plots. However, the plots would be useful for the characterization of sake in the case of a larger number of sake samples than in this study, because it contains more detailed information.

This method can be regarded as a rapid technique for the characterization of sake, because a sample can be characterized within $10 \mathrm{~min}$, including the procedures of both measurements and statistical analysis. The presented method would contribute to quality control and marketing studies for the brewers of sake. In addition, the characterization of sake by this method would be of some help for the selection of sake by consumers.

\section{Acknowledgements}

This work was supported by Shinshu University Satellite Venture Business Laboratory (SVBL). The authors were the members of "Project Device Experts (P-DEX)" organized by SVBL.

\section{References}

1. National Tax Agency of Japan, Statistical Information of Alcohol Tax, http://www.nta.go.jp/shiraberu/senmonjoho/ sake/tokei/mokuji.htm (in Japanese).

2. Y. Akiyama, "Nihon-shu (Japanese Sake, in Japanese)", 1994, Iwanami Shoten, Tokyo.
3. A. Miki, A. Isogai, H. Utsunomiya, and H. Iwata, J. Biosci. Bioeng., 2005, 100, 178.

4. A. Isogai, H. Utsunomiya, R. Kanda, and H. Iwata, J. Agric. Food Chem., 2005, 53, 4118.

5. A. Yasuhara, K. Kawada, and T. Shibamoto, J. Agric. Food Chem., 1998, 46, 2664.

6. A. S. Araújo, L. L. da Rocha, D. M. Tomazela, A. C. H. F. Sawaya, R. R. Almeida, R. R. Catharino, and M. N. Eberlin, Analyst, 2005, 130, 884.

7. J. K. S. Møller, R. R. Catharinob, and M. N. Eberlin, Analyst, 2005, 130, 890.

8. R. R. Catharino, I. B. S. Cunha, A. O. Fogaça, E. M. P. Facco, H. T. Godoy, C. E. Daudt, M. N. Eberlin, and A. C. H. F. Sawaya, J. Mass Spectrom., 2006, 41, 185.

9. P. P. de Souza, H. G. L. Siebald, D. V. Augusti, W. B. Neto, V. M. Amorim, R. R. Catharino, M. N. Eberlin, and R. Augusti, J. Agric. Food Chem., 2007, 55, 2094.

10. M. Hirotsune, A. Haratake, A. Komiya, J. Sugita, T. Tachihara, T. Komai, K. Hizume, K. Ozeki, and T. Ikemoto, J. Agric. Food Chem., 2005, 53, 948.

11. K. Hayakawa, K. Ando, N. Yoshida, A. Yamamoto, A. Matsunaga, M. Nishimura, M. Kitaoka, and K. Matsui, Biomed. Chromatogr., 2000, 14, 72.

12. T. Imanari and Z. Tamura, Agric. Biol. Chem., 1971, 35, 321.

13. F. Takenaka, H. Uchiyama, and T. Imamura, Biosci., Biotechnol., Biochem., 2000, 64(2), 378.

14. T. Asano, Seibutsu-kogaku, 2007, 85, 63. 